\title{
DETERMINAÇ̃̃O DA APTIDÃO AGRÍCOLA DA MICRORREGIÃo DE MOSSORÓ-RN
}

\author{
Jurema Maria Silva Araújo ${ }^{1}$, Herison Alves de Oliveira ${ }^{2}$, Hélio Nogueira Bezerra ${ }^{3}$, Paulo César Moura da Silva ${ }^{4}$
}

\section{RESUMO}

O presente trabalho objetivou determinar a aptidão agrícola de uma região de grande importância econômica, localizada no oeste potiguar. A microrregião de Mossoró é composta pelos municípios de Tibau, Grossos, Areia Branca, Baraúna, Mossoró e Serra do Mel. Foi utilizada a metodologia proposta pelo Serviço Nacional de Levantamento e Conservação do solo da Empresa Brasileira de Pesquisa Agropecuária (EMBRAPA), que classifica a aptidão das terras com relação à água, mecanização e fertilidade ligada às classes de solos verificadas na área. No desenvolvimento do trabalho utilizou-se o geoprocessamento através das ferramentas existentes nos Sistemas de Informações Geográficas (SIG), por meio de bases digitalizadas. A área de maior predominância referente à aptidão agrícola foi classificada como restrita para diferentes níveis tecnológicos, representando $71,67 \%$ da área em estudo. Verificou-se também áreas de aptidão agrícola regular e restrita para pastagem natural, $16,35 \%$ e 1,35\%, respectivamente. A região apresentou também $1,96 \%$ de sua área classificada como sendo de aptidão agrícola regular para lavouras para diferentes níveis de tecnologia, além de $8,68 \%$ da área classificada como inapta para a prática agrícola, restando apenas à preservação da fauna e da flora local.

Palavras-chave: Avaliação das terras, uso racional, geoprocessamento.

\section{ABSTRACT \\ DETERMINATION OF THE AGRICOLA SUSTAINABILITY IN THE MICROREGION OF MOSSORÓ- RN}

This study sought to determine the agricultural sustainability of a region of great economic importance, located in the western Potiguar. The micro-region of Mossoro is composed of the municipalities of Tibau, Grossos, Areia Branca, Baraúna, Mossoró and Serra do Mel. The methodology proposed by the National Service of Surveying and Soil Conservation of the Brazilian Company of Agricultural Research (EMBRAPA) was used, which classifies the sustainability of the land related to water, mechanization and fertility linked to the soil classification verified in the area. In the development of this paper the technology of geographic information systems (GIS) was implemented via digital databases. The area of greatest predominance in relation to agricultural suitability was classified as restricted for different technologic levels, representing $71.67 \%$ of the study area. Also verified were areas of regular and limited agricultural potential for natural pasture, $16.35 \%$ and $1.35 \%$ respectively. It was found that $1.96 \%$ of its area was classified as sustainable for crops of different technology levels. Additionally, $8.68 \%$ of the area was classified as unfit for agriculture practices, suitable only for preservation of local fauna and flora.

Keywords: Land evaluation, rational use, geoprocessing.

\section{Recebido para publicação em 05/10/2011. Aprovado em 14/03/2013.}

1 - Engenheira Agrícola e Ambiental, mestranda em Engenharia Sanitária pela UFRN/ Natal-RN, jurema.araujo@hotmail.com;

2 - Engenheiro Agrícola e Ambiental, mestrando em Engenharia Sanitária pela UFRN/ Natal-RN, herisonalves@yahoo.com.br;

3 - Engenheiro Agrícola e Ambiental, mestrando em Engenharia Sanitária pela UFRN/ Natal-RN, helhimnogueira@hotmail.com;

4 - Engenheiro Agrônomo, professor adjunto da UFERSA/Mossoró-RN, paulo.moura@ufersa.edu.br.

\section{REVENG}




\section{INTRODUÇÃO}

O solo caracteriza-se como recurso de grande importância para diversas atividades econômicas, sobretudo para a agricultura. Torna-se necessário a adoção de estratégias de interpretação que permitam seu uso racional (MOURA et al., 2007). Surgiram então os sistemas que classificam os solos com relação a sua aptidão agrícola e potencial do uso das terras. Dentre os existentes destaca-se o "Sistema de Avaliação da Aptidão Agrícola das Terras (SAAT)" (RAMALHO FILHO; BEEK, 1995).

Uma série de pesquisas vem sendo desenvolvidas através do emprego do SAAT, com a intenção de determinar a aptidão agrícola em diferentes regiões do Brasil. Dentre elas estão trabalhos desenvolvidos por Hamada et al. (2006), Vasconcelos Gomes et al. (2005), Calderano Filho et al. (2004), e Silva et al. (2010).

Corseuil et al. (2009) dizem que a avaliação das terras consiste no processo de estimar a sua aptidão, quando utilizada para fins específicos, envolvendo a execução e interpretação de estudos sobre o solo, vegetação, clima, relevo entre outros aspectos, de modo a identificar e comparar os tipos de uso da terra mais adequados para uma determinada região.

Trata-se, portanto, de um processo interpretativo que considera informações sobre características do meio ambiente, de atributos do solo e da viabilidade de melhoramento das qualidades básicas das terras (PEREIRA et al., 2006).

De acordo com Godoy e Lopes-Assad (2002) um sistema de aptidão agrícola das terras para culturas específicas deve quantificar os fatores condicionadores da produção, conforme o nível de manejo a ser adotado, pela seleção de características que permitam identificar os riscos decorrentes das atividades agrícolas.

Nascimento et al. (2004) comentam que a avaliação da aptidão das terras é importante e necessária, pois dá suporte a elaboração de zoneamentos e estabelece o uso dos recursos naturais segundo a aptidão, evitando situações de subutilização ou sobreutilização.

Atualmente, novas tecnologias e técnicas, tais como o geoprocessamento, estão sendo amplamente aplicadas com o objetivo de fornecer informações eficientes para a elaboração de mapas de aptidão agrícola das terras, que por sua vez servem de ferramenta para auxiliar na tomada de decisões no que se refere ao planejamento e exploração dos solos de forma compatível com seus distintos usos (CARLOS JÚNIOR, 2009).

Em função das respostas positivas obtidas através do uso de geoprocessamento em estudos ambientais, vários trabalhos vêm sendo conduzidos com o propósito de avaliar a aptidão agrícola das terras, bem como delimitar a partir da confecção de mapas áreas propícias para diferentes atividades agrícolas (CARLOS JÚNIOR, 2009).

As tecnologias de geoprocessamento são instrumentos apropriados para o manuseio, manutenção, gerenciamento e disponibilização de informações com características espaciais. A disponibilização de informações em formato digital possibilita a manipulação e apresentação do conhecimento geográfico humano segundo novas formas, práticas e atrativas, bem como uma redução nos custos dos processos de atualização e substituição. Os produtos gerados a partir da ferramenta de manipulação denominada de Sistema de Informação Geográfica (SIG) podem ser atualizados, editados, impressos e duplicados mais rápidos e facilmente do que aqueles gerados por métodos tradicionais. (SALBEGO et al., 2006).

O Geoprocessamento atua nas mais diversas áreas e gera importantes informações sobre o uso atual de solos, zoneamentos, classificações técnicas, planejamento ambiental integrado, monitoramento de impactos ambientais, dentre outros, caracterizando-o como uma excelente ferramenta de apoio e viabilização de projetos, tendo em vista que os dados trabalhados servem de base para o planejamento e gestão do espaço geográfico. (PEREIRA, 2002).

Diversos trabalhos têm utilizado a tecnologia dos SIG's visando o diagnóstico ambiental e a análise das potencialidades existentes em determinada região (LOPES-ASSAD, 1995; ARAÚJO; LOPESASSAD, 2001; GODOY; LOPES-ASSAD, 2002).

O objetivo deste trabalho é estudar o potencial agrícola das terras localizadas na Microrregião de Mossoró, que é um forte pólo da fruticultura irrigada do país, permitindo assim que o conhecimento adquirido seja utilizado para que a atividade agrícola na área de estudo seja realizada de forma racional, sustentável e com o maior aproveitamento possível. 


\section{MATERIAL E MÉTODOS}

Este trabalho teve como objeto de estudo a área formada pela Microrregião de Mossoró que conta com seis municípios: Areia Branca, Baraúna, Grossos, Mossoró, Serra do Mel e Tibau, que totalizam 427.178 hectares, conforme dados do IBGE 2010, a população total nos seis municípios é de 304.322 mil habitantes (Figura 1).

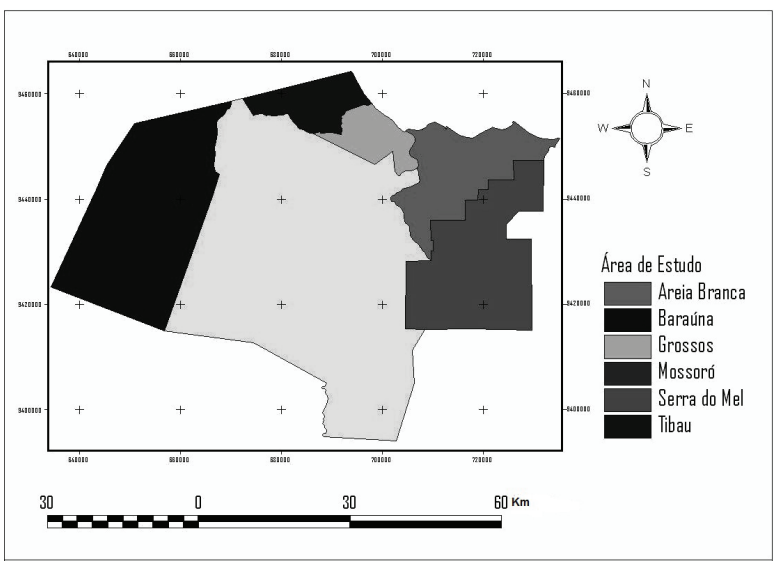

Fonte: Adaptado pela pesquisadora através de dados da IBGE (2005).

Figura 1. Mapa de localização da microrregião de Mossoró.

A região apresenta clima tipicamente semiárido, o qual provoca uma grande evaporação $\mathrm{e}$ concentração de sais na parte superficial do terreno.

A área em estudo apresenta vegetação de três tipos. A caatinga Hiperxerófila é vegetação de caráter mais seco, com abundância de cactáceas e plantas de porte mais baixo e espalhado. Entre outras espécies destacam-se a jurema-preta, mufumbo, faveleiro, marmeleiro, xique-xique e facheiro. A vegetação Carnaubal é vegetação natural onde as espécies predominantes são palmeiras e carnaúbas. Os carnaubais são espaçados e iluminados e a vegetação halófila suporta grande salinidade em decorrência da penetração da água do mar nas regiões baixas marginais dos cursos d'água (IDEMA, 2008).

Geologicamente a região situa-se em área de abrangência da Bacia Potiguar e Grupo Barreiras, onde predominam calcarenitos e calcilutitos bioclásticos, cinza claros a amarelados, com níveis evaporíticos na base, depositados em extensa planície de maré e numa plataforma rasa, da Formação Jandaíra (Bacia Potiguar) de Idade do Cretácea (IDEMA, 2008).
A região de estudo apresenta fundamental importância econômica em nível regional, pois nela estão concentrados $45 \%$ da produção de sal marinho do Brasil e o maior campo de exploração petrolífera do país em terra, causando crescente aumento nas tensões ambientais nos municípios que a compõem.

Para a realização da pesquisa foi utilizada a tecnologia dos Sistemas de Informações Geográficas (SIG), a qual possibilitou a geração de todo o material cartográfico, além de relatórios, tabelas e gráficos contendo os dados necessários ao seu desenvolvimento. Com o objetivo do fornecimento de suporte a pesquisa realizada foram utilizados microcomputador e os softwares SIG Terra View 3.5, Corel Draw e Microsoft Office (Word e Excel).

Como base de dados utilizou-se o Mapa Exploratório/Reconhecimento de Solos, escala de 1:300.000, de fonte do MA/EMBRAPA/SUDENE (1979) e o Mapa Político-Administrativo do Estado do Rio Grande do Norte, de fonte do IBGE (2005), ambos em formato digital. Para elaboração de mapas e produtos cartográficos utilizou-se como sistema de unidade cartográfica o Sistema de Coordenadas UTM, SAD 69 ZONA 24.

A avaliação da aptidão agrícola foi feita através da análise de dados dos diferentes níveis de manejo, exigência quanto à aplicação de insumos, possibilidade de mecanização e grupos de aptidão, tendo como base a metodologia proposta pelo Sistema de Avaliação da Aptidão Agrícola das Terras, do Serviço Nacional Levantamento e Conservação de Solos/EMBRAPA (RAMALHO FILHO; BEEK, 1995).

A classificação foi realizada de acordo com a metodologia do Levantamento Exploratório/ Reconhecimento de Solos do Estado do Rio Grande do Norte (MA/EMBRAPA/SUDENE, 1971), tendo sido atualizada segundo o Sistema Brasileiro de Classificação de Solos (EMBRAPA, 2006).

Foi realizado o cruzamento das informações disponíveis no mapa de solos fornecido pela EMBRAPA com os dados de classificação das terras em relação à aptidão agrícola, níveis de exigência quanto à aplicação de insumos, como fertilizantes, corretivos e práticas conservacionistas, e quanto às possibilidades de mecanização, extraído do levantamento de aptidão agrícola das terras do 
Quadro 1. Simbologia correspondente ás classes de aptidão agrícola

\begin{tabular}{ccccccc}
\hline Classes de Aptidão & \multicolumn{3}{c}{$\begin{array}{c}\text { Lavoura } \\
\text { Níveis de manejo }\end{array}$} & Pastagem plantada & Silvicultura & Pastagem nativa \\
& A & B & C & Nível B & Nível B & Nírel A \\
\hline Boa & A & B & C & P & S & N \\
Regular & A & B & C & P & S & N \\
Restrita & (a) & (b) & (c) & (p) & (s) & (n) \\
Inapta & - & - & - & - & - & - \\
\hline
\end{tabular}

Rio Grande do Norte, do Ministério da Agricultura (MINISTÉRIO DA AGRICULTURA, 1978), gerando um plano de informação referente aos fatores limitantes para a determinação do mapa de aptidão agrícola, que pode ser observado no Quadro 1 abaixo.

Inicialmente relacionou-se as informações contidas no mapa político-administrativo da microrregião de Mossoró com o seu respectivo mapa de solos, gerando uma carta que contém as classes texturais de solos predominantes na região. Feito isso, cruzou-se também informações referentes aos diferentes níveis de manejo e fatores limitantes, gerando mapas, tabelas e gráficos importantes para a compreensão. Por fim, elaborouse o mapa de aptidão agrícola das terras.

\section{RESULTADOS E DISCUSSÃO}

Conforme o Sistema Brasileiro de Classificação de Solos (EMBRAPA 2006), a microrregião de
Mossoró apresenta quatorze classes de solos, as quais são ARGISSOLOS, CAMBISSOLOS, CHERNOSSOLOS, GLEISSOLOS, LATOSSOLOS, NEOSSOLOS E VERTISSOLOS (Figura 2).

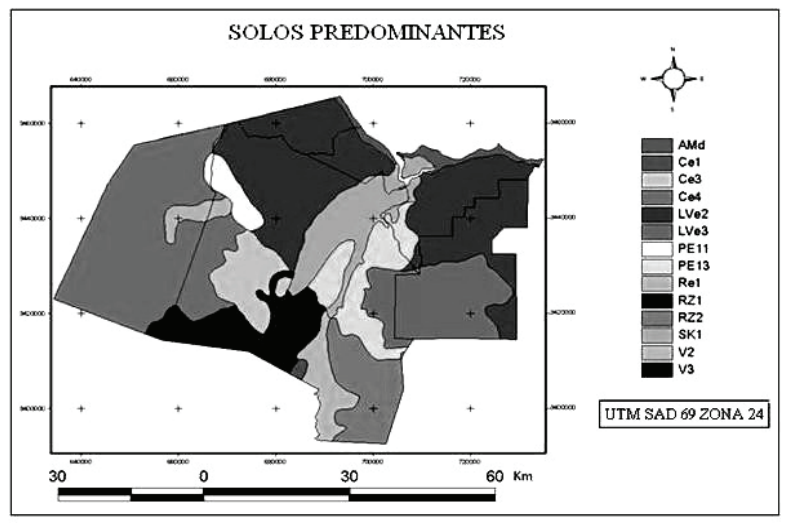

Fonte: Adaptado pela pesquisadora através de dados da EMBRAPA (1971).

Figura 2. Mapa das classes de solos predominantes da microrregião de Mossoró.

Quadro 2. Classes de solos predominantes da microrregião de Mossoró

\begin{tabular}{cccc}
\hline Tipos de Solos & Classe Atual & Área (ha) & Percentagem (\%) \\
\hline AMd - Areias Quartzosas Marinhas Distróficas & NEOSSOLO & $6.729,89$ & 1,59 \\
Ce1- Cambissolo Eutrófico & CAMBISSOLO & $1.013,37$ & 0,24 \\
Ce3- Cambissolo Eutrófico & CAMBISSOLO & $18.882,21$ & 4,45 \\
Ce4- Cambissolo Eutrófico & CAMBISSOLO & $97.397,63$ & 22,95 \\
LVe2- Latossolo Vermelho Amarelo Eutrófico & LATOSSOLO & $116.802,75$ & 27,52 \\
LVe3- Latossolo Vermelho Amarelo Eutrófico & LATOSSOLO & $42.034,44$ & 9,90 \\
PE11- Podzólico Vermelho Amarelo Equivalente Eutrófico & ARGISSOLO & $8.295,99$ & 1,96 \\
PE13- Podzólico Vermelho Amarelo Equivalente Eutrófico & ARGISSOLO & $28.060,14$ & 6,61 \\
Re1- Solos Litólicos Eutrófico & NEOSSOLO & $5.736,02$ & 1,35 \\
RZ1- Rendzina & CHERNOSSOLO & $26.435,83$ & 6,23 \\
RZ2- Rendzina & CHERNOSSOLO & $25.462,57$ & 6,00 \\
SK1- Solonchak Solonétzico & GLEISSOLO & $30.091,49$ & 7,09 \\
V2-Vertissolo & VERTISSOLO & $12.708,21$ & 2,99 \\
V3-Vertissolo & VERTISSOLO & $4.793,86$ & 1,13 \\
TOTAL & & $424.444,40$ & 100,00 \\
\hline
\end{tabular}

Fonte: Adaptado pela pesquisadora através de dados da EMBRAPA (1971). 
$\mathrm{Na}$ microrregião de Mossoró, o solo que apresenta a maior extensão é o Latossolo Vermelho Amarelo Eutrófico, ocupando área de 158.837,19 hectares, equivalendo a $37,42 \%$ da região estudada e que segundo o Sistema Brasileiro de Classificação de Solos (EMBRAPA, 2006) faz parte do grupo dos latossolos. Estendem-se pelos municípios de Tibau, Grossos, Areia Branca, Mossoró e Serra do Mel.

Na região de Serra do Mel, a utilização que se dá para este solo é o cultivo do cajueiro. Isto se deve ao fato do solo apresentar boas características físicas, possuindo estrutura granular, oferecendo possibilidade de se plantar diversas culturas, proporcionando-as um bom desenvolvimento do sistema radicular. Desta forma pode-se ter grande aproveitamento agrícola caso o déficit hídrico deixe de ser fator limitante das produções. Ao se aproximar do litoral, ocorre transição de Latossolo para Neossolo, a vegetação torna-se aparentemente mais seca, fato este que se deve a presença de material ou areia mais grossa.

Em seguida tem-se o Cambissolo Eutrófico que faz parte do grupo dos Cambissolos e apresenta área de 117.293,21 hectares, correspondente a 27,64\% da área da Microrregião de Mossoró. Esta classe de solo está presente nos municípios de Baraúna e Mossoró. Tais solos possuem fertilidade natural alta e relevo plano. E da mesma forma que o Latossolo, apresenta limitação de água bastante acentuada, juntamente com eventual presença de pedras na parte superficial ou interna. Em determinadas regiões referentes a este solo há grande aproveitamento agrícola, sobretudo em Baraúna, com o cultivo de diversas culturas como banana, melão, mamão e manga.

Está presente nos municípios de Baraúna, Mossoró e Areia Branca o solo classificado como Podzólico Vermelho Amarelo Equivalente Eutrófico, que pertence à classe dos Argissolos, abrangendo área de 36.356,13 hectares, equivalente a $8,57 \%$ da área da Microrregião de Mossoró. Assim como os solos citados acima, possui boas condições para a produção agrícola, possuindo apenas limitações hídricas. No caso dos locais que possuem argila de alta atividade no horizonte $\mathrm{B}$ a limitação de água é atenuada devido à alta capacidade de retenção que os mesmos possuem.

Tem-se também, os solos classificados como Areias Quartzosas Marinhas Distróficas e Solonchak Solonétzico, pertencentes a classe dos Neossolos e Gleissolos, respectivamente. Os primeiros são solos pobres encontrados na microrregião de Mossoró e inviáveis para a prática agrícola, localizadas nos municípios de Tibau, Grossos e Areia Branca. No último caso tem-se um solo bastante encharcado, mal drenado, com a presença de sódio e apresentando alta concentração de argila 1:1. Nestas áreas existe a extração de petróleo. Encontram-se presentes nas áreas de Grossos, Mossoró e Areia Branca. Juntos abrangem ocupam área total de 36.821,38 hectares , ou seja, $8,68 \%$ da Microrregião.

Outra classe de solo encontrada foi a Rendzina, com área de 51.898,40 hectares, correspondentes a $12,23 \%$ da microrregião e atualmente fazendo parte da classe Chernossolo.

Os Solos Litólicos Eutróficos são praticamente não cultivados devido à baixa profundidade e a limitação de água. Na área em estudo abrangem apenas 5.736,02 hectares, ou seja, $1,35 \%$ da área total (Microrregião de Mossoró). Os Vertissolos encontrados no local também correspondem a uma pequena extensão se comparados aos outros tipos de classificação $(4,12 \%)$, ou seja, 6.002,07 hectares.

Nos níveis de manejo A e B, caracterizados pelas práticas agrícolas de baixo e moderado nível técnico-cultural, respectivamente, a única limitação encontrada foi referente à deficiência hídrica $(\mathrm{H})$, sendo uma limitação primária e abrangendo área de $387.623,02$ hectares, $91,32 \%$ da totalidade da região, em ambos os casos.

O restante da área é classificada como inapta, correspondendo a extensão de 36.821,38 hectares ( $8,68 \%$ da área da Microrregião). A inaptidão devese ao fato de no local está presente o solo da classe Solonchak Solonétzico, que é caracterizado pela alta salinidade, chegando a apresentar crostas superficiais de sal durante período de estiagem, além da presença de Areias Quartzosas Marinhas Distróficas, presentes em todos os municípios litorâneos. Estendem-se pelos municípios de Tibau, Grossos, Areia Branca e Mossoró (Figura 3 e Quadro 3).

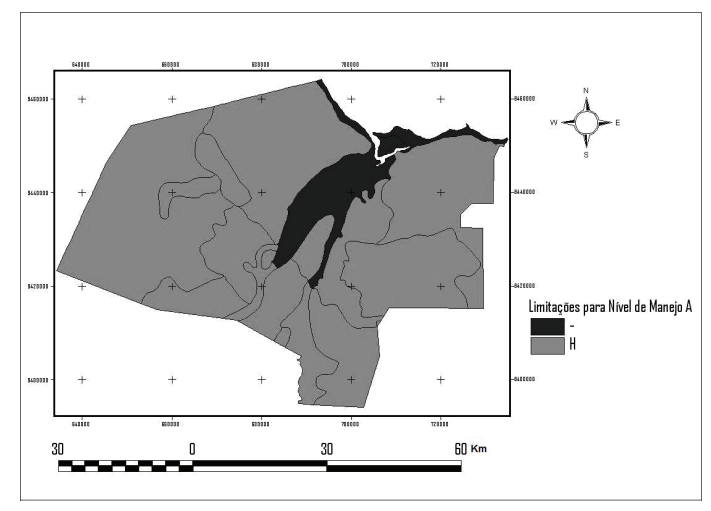

Fonte: Adaptado pela pesquisadora através de dados da EMBRAPA (1971).

Figura 3. Mapa das limitações para onível de manejo A e B da microrregião de Mossoró. 
Quadro 3. Limitações para o nível de manejo A e B da microrregião de Mossoró

\begin{tabular}{ccc}
\hline Limitações para Nível de Manejo A e B & Área (ha) & Percentagem (\%) \\
\hline- & 36821.38 & 8.68 \\
H & 387623.02 & 91.33 \\
TOTAL & 424444.40 & 100.00
\end{tabular}

Fonte: Adaptado pela pesquisadora através de dados da EMBRAPA (1971).

A única limitação existente tem como causas as características climáticas do local, visto que, a área de estudo está inserida em uma região que apresenta baixo índice pluviométrico, com chuvas distribuídas em curto espaço de tempo. Esta situação poderá ser resolvida com a utilização de sistemas de irrigação no manejo agrícola.

A principal limitação para o nível de manejo $\mathrm{C}$ permanece sendo representada pela deficiência hídrica, o que corresponde a uma área de $312.486,53$ hectares, $73,62 \%$ da microrregião. Porém, comparando-se a questão da deficiência hídrica entre os três níveis de manejo observa-se uma redução considerável desta limitação nesta última situação. (Figura 4 e Quadro 4).

Apenas 25.462,57 hectares, ou seja, 6,00\% da microrregião de Mossoró tem limitação primária referente à mecanização. Essa limitação está inserida na área que corresponde ao solo do tipo Rendzina, e deve-se provavelmente ao fato desse solo possuir uma pequena porção intermediária com solos da classe Litólicos Eutróficos (proporção de 15\%) na fase rochosa, além de baixa profundidade.

Observou-se uma extensão de $32.171,85$ hectares, correspondentes a 7,58\% da área em estudo, com limitação primária para a mecanização e secundária para a deficiência hídrica. Estas áreas correspondem a solos da classe Litólicos Eutróficos e Rendzina, respectivamente. Ambos os casos possuem fases rochosas nas suas associações com outros solos, e no primeiro caso há o afloramento de rocha na proporção de $35 \%$.

A área em estudo apresentou uma extensão de 17.502,07 hectares (4,12\%), com limitação primária a deficiência hídrica e secundária a mecanização, que corresponde aos Vertissolos.

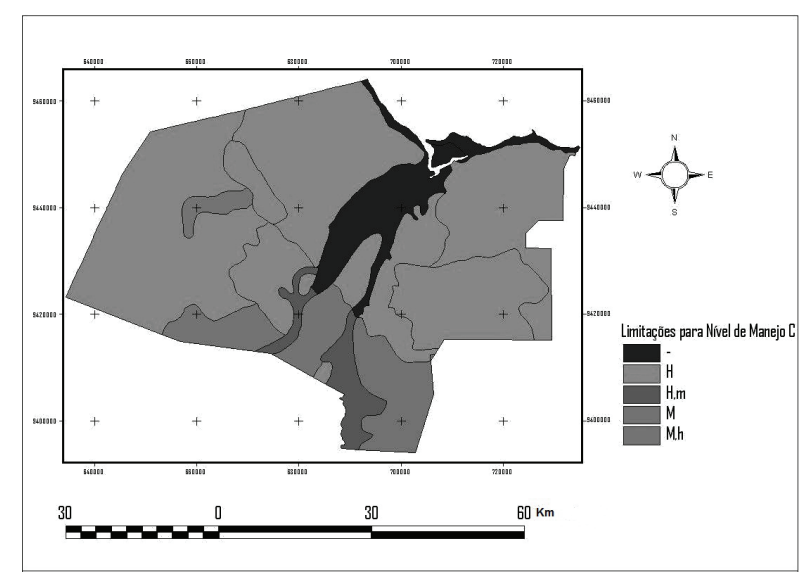

Fonte: Adaptado pela pesquisadora através de dados da EMBRAPA (1971).

Figura 4. Mapa das limitações para o nível de manejo C da microrregião de Mossoró.

Este fato faz com que seja possível a utilização de máquinas agrícolas no manejo do solo na maior parte da microrregião, participando de processos como escarificação e gradagem, em grande parte da região. Sendo características de práticas altamente tecnológicas e que são intrínsecas ao nível de manejo C.

Emrelação a classificação das terras em exigência de fertilizantes e corretivos, a microrregião de Mossoró apresentou três unidades de mapeamento. Classificadas como exigência baixa e média, $F 1$, $F 2$, respectivamente, junto com a região que não possui aptidão para a prática agrícola. 
Quadro 4. Limitações para o nível de manejo C da microrregião de Mossoró

\begin{tabular}{ccc}
\hline Limitações para Nível de Manejo C & Área (ha) & Percentagem (\%) \\
\hline H & 36821.38 & 8.68 \\
H,M & 312486.53 & 73.62 \\
M & 17502.07 & 4.12 \\
M,H & 25462.57 & 6.00 \\
TOTAL & 32171.85 & 7.58 \\
\hline
\end{tabular}

Fonte: Adaptado pela pesquisadora através de dados da EMBRAPA (1971).

Quadro 5. Exigências em fertilizantes e corretivos das terras da microrregião de Mossoró

\begin{tabular}{ccc}
\hline Fertilizantes e Corretivos & Área (ha) & Percentagem (\%) \\
\hline- & 36821.38 & 8.68 \\
F1 & 228785.83 & 53.90 \\
F2 & 158837.19 & 37.42 \\
\hline TOTAL & 424444.40 & 100.00 \\
\hline
\end{tabular}

Fonte: Adaptado pela pesquisadora através de dados da EMBRAPA (1971).

A maior área mapeada refere-se ao nível de exigência baixo de fertilizantes e corretivos $F 1$ com área de 228.785,83 hectares que corresponde a 53,90\% da região estudada (Figura 5 e Quadro 5). Esta área estende-se pelos municípios de Mossoró e Baraúna. Dentre os fatores que contribuíram para esta classificação está a presença do Cambissolo, sobretudo na região de Baraúna, onde há grande produtividade agrícola. Esses tipos de solos por serem pouco evoluídos, apresentam altos teores de minerais primários, que se imtemperizam e se tornam fontes de nutrientes para as plantas.

A área total correspondente a exigência média de fertilizantes e corretivos abrange uma extensão de $158.837,19$ ha, $37,42 \%$ do total da área estudada. Presente em todos os municípios, com exceção de Baraúna, corresponde ao Latossolo.

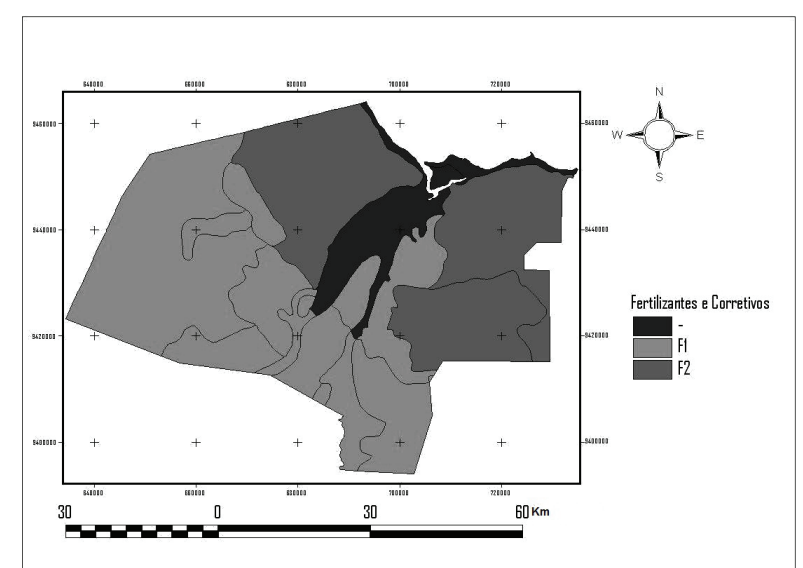

Fonte: Adaptado pela pesquisadora através de dados da EMBRAPA (1971).

Figura 5. Mapa das exigências em fertilizantes e corretivos das terras da microrregião de Mossoró.

\section{REVENG}


As práticas conservacionistas consistem no emprego de técnicas que evitam os processos erosivos no solo. As características do solo presente em determinada área influenciam diretamente a definição da prática conservacionista a ser utilizada, que dependendo do manejo reduzirá a erosão em diferentes níveis. As principais características do solo que influenciam esta tomada de decisão são: estrutura, granulometria e profundidade, que juntamente com as características do meio ambiente em que estão inseridos, tal como declividade, potencializam ou reduzem a ocorrência dos processos erosivos.

$\mathrm{Na}$ região em estudo foram detectadas apenas duas unidades de mapeamento quanto à classificação das exigências em práticas conservacionistas. A região de menor extensão refere-se à área inapta a prática agrícola, ao passo que, a de a maior extensão à baixa exigência de práticas conservacionistas, $C 1$. Esta apresenta área de 387.623,02 hectares, abrangendo 91,32\% da área total (Figura 6 e Quadro 6).

Os municípios de Baraúna e Serra do Mel apresentaram a sua totalidade classificada com a unidade de mapeamento acima.

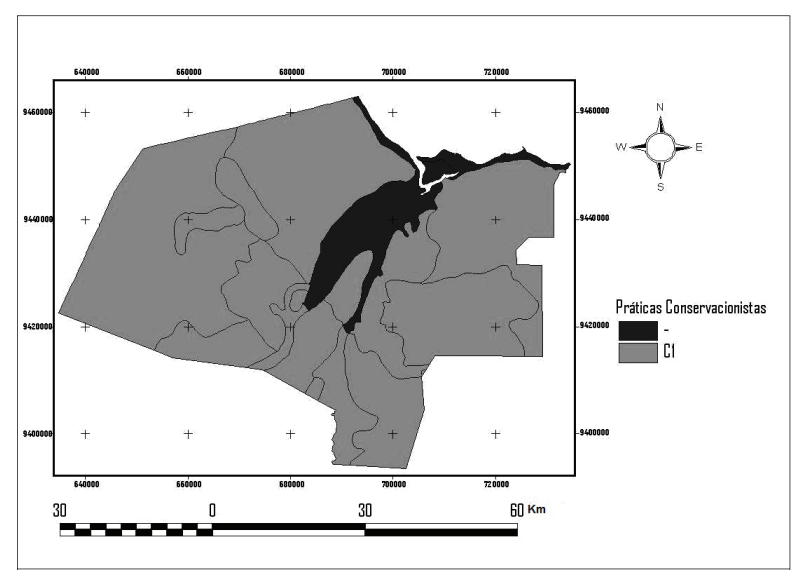

Fonte: Adaptado pela pesquisadora através de dados da EMBRAPA (1971).

Figura 6. Mapa das exigências em práticas conservacionistas das terras da microrregião de Mossoró.
Quanto à classificação em relação aos níveis de possibilidade de mecanização, a microrregião de Mossoró apresentou quatro unidades de mapeamento, mais a região inapta a agricultura. A primeira representada pela alta capacidade de mecanização (M1) apresentou área de 284.426,39 hectares, possuindo então a maior extensão em relação às outras classes, 67,00\% da Micorregião de Mossoró, e estando presente em todos os municípios (Figura 7 e Quadro 7).

A unidade de mapeamento classificada como média possibilidade de mecanização (M2) apresentou uma área equivalente a 45.562,21 hectares, 10,74\% da área de estudo, caracterizando os municípios de Mossoró e Areia Branca. Os solos encontrados nessa área são pertencentes a classe dos Vertissolos e o Podzólico Vermelho Amarelo Equivalente Eutrófico e sua relação com a capacidade quanto à mecanização pode ser explicada devido a pequenas porções caracterizadas com o relevo suave ondulado.

Já a terceira unidade, M3, que caracteriza região com baixa possibilidade de mecanização possui uma extensão de 5.736,02 hectares correspondendo à menor unidade de mapeamento com apenas 1,35\% da área total, porém abrange todos os municípios da microrregião. O solo presente faz parte da classe Litólico Eutrófico, que possui fase rochosa e uma porção que contém afloramento de rocha.

Por fim, temos a unidade $M 4$, que indica regiões com possibilidades de mecanização muito baixas, localizadas nos solos da classe Rendzinas. Essa classificação ocupa o segundo lugar em extensão, abrangendo uma área de 51.898,40 hectares, que corresponde a $12,23 \%$ da microrregião de Mossoró. Foram observadas nessa mesma área limitações primárias para a mecanização no nível de manejo $\mathrm{C}$, devido a presença de fase rochosa.

Quadro 6. Exigências em práticas conservacionistas das terras da microrregião de Mossoró

\begin{tabular}{ccc}
\hline Práticas Conservacionistas & Área (ha) & Percentual (\%) \\
\hline- & 36821.38 & 8.68 \\
C1 & 387623.02 & 91.33 \\
TOTAL & 424444.40 & 100.00 \\
\hline
\end{tabular}

Fonte: Adaptado pela pesquisadora através de dados da EMBRAPA (1971). 


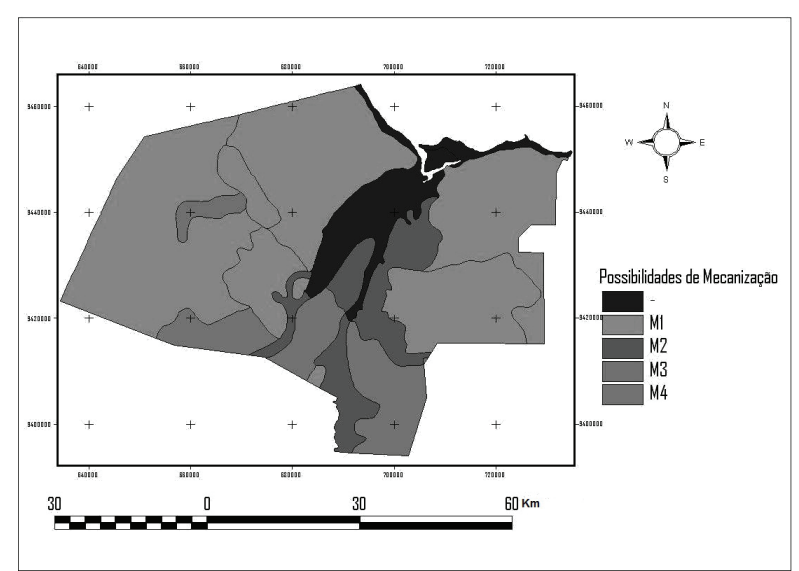

Fonte: Adaptado pela pesquisadora através de dados da EMBRAPA (1971).

Figura 7. Mapa da possibilidade de mecanização das terras da microrregião de Mossoró.

De acordo com o sistema de avaliação de aptidão agrícola considerado, as terras da microrregião de Mossoró apresentaram cinco unidades de mapeamento de aptidão. A classificação de tais unidades com suas respectivas áreas e características se apresentou da seguinte forma (Figura 8 e Quadro 8):

2abc* - Terras pertencentes à classe de aptidão agrícola regular para lavouras nos níveis de manejo $A, B$ e $C$, aptas para culturas de ciclo curto. A área ocupada por essas terras é de 8.295,99 hectares ( $1,96 \%$ da área da microrregião), se estendendo por dois municípios, Baraúna e Mossoró. $3(\mathrm{abc})^{*}$ - Terras pertencentes à classe de aptidão agrícola restrita nos níveis de manejo $A, B$ e $C$, aptas para culturas de ciclo longo. A área ocupada por essas terras é de 304.190,54 hectares $(71,67 \%$ da área da microrregião), é a que apresenta maior área ocupada, se estendendo pelos seis municípios (Baraúna, Mossoró, Tibau, Grossos, Areia Branca e Serra do Mel).

$5 n$ - Terras pertencentes á classe de aptidão agrícola regular para pastagem natural e à classe inapta para silvicultura, sem restrição quanto ao ciclo das culturas. Sua área de ocupação é de 69.400,46 hectares $(16,35 \%$ da área da microrregião), distribuída por dois municípios (Baraúna e Mossoró).

5(n) - Terras pertencentes à classe de aptidão restrita para pastagem natural, no nível de manejo $A$, e inapta para silvicultura. Essas terras apresentam uma área de 5.736,02 hectares $(1,35 \%$ da área da microrregião), situada nos municípios de Baraúna e Mossoró.

6 - Terras sem aptidão para uso agrícola, restando apenas preservar a flora e a fauna estabelecida no local. Essas terras estão distribuídas nos três municípios litorâneos (Tibau, Grossos e Areia Branca) e no município de Mossoró, ocupando um total $36.821,38$ hectares $(8,68 \%$ da área da microrregião).

Quadro 7. Possibilidade de mecanização das terras da microrregião de Mossoró

\begin{tabular}{ccc}
\hline Possibilidade de Mecanização & Área (ha) & Percentagem (\%) \\
\hline M1 & 36821.38 & 8.68 \\
M2 & 284426.39 & 67.01 \\
M3 & 45562.21 & 10.74 \\
M4 & 5736.02 & 1.35 \\
TOTAL & 51898.40 & 12.23 \\
\hline
\end{tabular}

Fonte: Adaptado pela pesquisadora através de dados da MBRAPA (1971). 
Quadro 8. Classificação da aptidão agrícola das terras da microrregião de Mossoró

\begin{tabular}{ccc}
\hline Possibilidade de Mecanização & Área (ha) & Percentagem (\%) \\
\hline $2 \mathrm{abc} *$ & 8295.99 & 1.96 \\
$3(\mathrm{abc})^{*}$ & 304190.54 & 71,67 \\
$5(\mathrm{n})$ & 5736.02 & 1.35 \\
$5 \mathrm{n}$ & 69400.46 & 16.35 \\
6 & 36821.38 & 8.68 \\
TOTAL & 424444.40 & 100.00 \\
\hline
\end{tabular}

Fonte: Adaptado pela pesquisadora através de dados da EMBRAPA (1971).

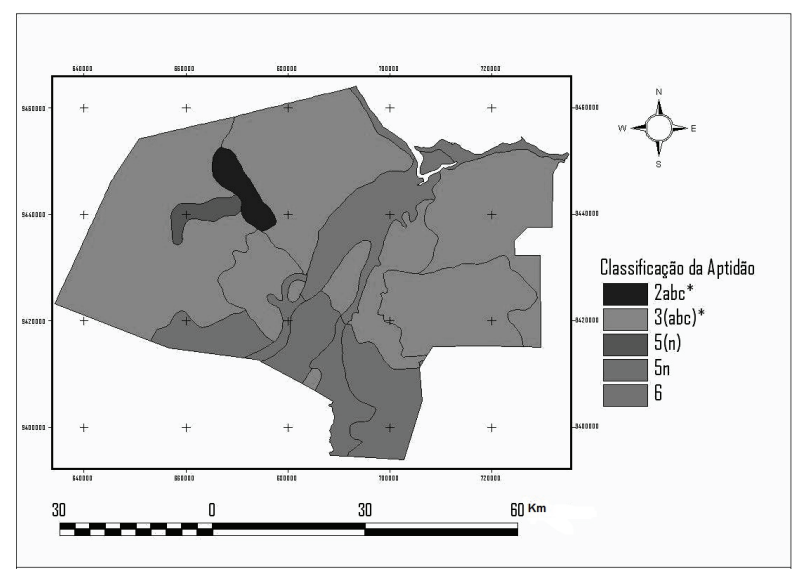

Fonte: Adaptado pela pesquisadora através de dados da EMBRAPA (1971).

Figura 8. Mapa das classes de aptidão agrícola das terras da microrregião de Mossoró.

Os resultados obtidos estão destacados na tabela abaixo (Quadro 8), onde existe a predominância da área classificada como pertencente à classe de aptidão agrícola restrita nos níveis de manejo $A, B$ e $C$, aptas para culturas de ciclo longo, correspondendo a $71,67 \%$ da área da microrregião.

\section{CONCLUSÕES}

- Conclui-se que a microrregião de Mossoró possui boas condições para a produção agrícola no local, pois os solos caracterizam-se por apresentarem bom grau de fertilidade, baixa exigência em práticas conservacionistas, e a maior parte é classificada com alta possibilidade de mecanização. A principal limitação das terras é referente à deficiência hídrica, em todos os diferentes níveis de manejo.

\section{REFERÊNCIAS BIBLIOGRÁFICAS}

ARAÚJO, A.G. ; LOPES ASSAD, M.L. Zoneamento de risco climático por cultura a partir de levantamento de solos de baixa intensidade. Revista Brasileira de Ciência do Solo, Viçosa, v.25, n.1, p.103-111, 2001

CALDERANO FILHO, B.; SANTOS, H.G.; RAMALHO FILHO, A.; CLAES SEN, M.E.C. ; CARVALHO JUNIOR, W. ; CHAGAS, C.S.; CALDERANO, S.B.; LUZ, L.D.; MOTCHI, E.P. \& WITTERN, K.P. Avaliação da aptidão agrícola das terras da microbacia do Córrego da Tábua, no município de São Fidélis, RJ. Rio de Janeiro: Embrapa Solos Boletim de Pesquisa e Desenvolvimento, 47, 2004. 43p.

CARLOS JÚNIOR, A.A. Uso de geotecnologias na avaliação da aptidão agrícola das terras da microrregião de Umarizal. 2009. 61f. Monografia (Graduação em Engenharia Agrícola) - Universidade Federal Rural do Semi-Árido, Mossoró, RN. 
CORSEUIL, C.W.; CAMPOS, S.; RIBEIRO, F.L.; PISSARRA, T.C.T.; RODRIGUES, F.M. Geoprocessamento e sensoriamento remoto aplicado na determinação da aptidão agrícola de uma microbacia. Revista Irriga, Botucatu, v.14, n.1, p.12-22, 2009.

EMBRAPA. Mapa de Solos do Levantamento Exploratório: reconhecimento dos solos do Estado do Rio Grande do Norte. Escala 1:1.000.000, 1971.

EMBRAPA. Sistema Brasileiro de Classificação de Solos. 2.ed. Rio de Janeiro, 2006. 306p.

GODOY, M.J.S.; LOPES-ASSAD, M.L. Aptidão agrícola de terras com estimativa de risco climático para a cultura do milho utilizando geoprocessamento. Revista Brasileira de Ciência do Solo, Viçosa, v.26, n.4, p.685-694, 2002.

HAMADA, E.; LOPES ASSAD, M.L. \& PEREIRA, D.A. Aptidão agrícola na área de recarga do Aquífero Guarani: Caso da microbacia hidrográfica do Córrego do Espraiado, Ribeirão Preto, SP. Engenharia Ambiental: Pesquisa e Tecnologia, Espírito Santo do Pinhal, v.3, n.1, p.62-71, 2006.

IBGE, Instituto Brasileiro de Geografia e Estatística. Censo 2010. Disponível em: http:// www.ibge.gov.br/home/download/estatistica.shtm Acesso em 13 ago. 2011.

IBGE, Instituto Brasileiro de Geografia e Estatística. Mapa Político-Administrativo do Estado do Rio Grande do Norte. 2005.

IDEMA, Instituto de Desenvolvimento Sustentável e Meio Ambiente. Anuário Estatístico 2008. Disponível em: http://www.idema.rn.gov. br/contentproducao/aplicacao/idema/socio economicos/arquivos/Anuario-CDROM\%202010/ index.htm Acesso em: 11 ago. 2011.

LOPES ASSAD, M.L. Uso de um sistema de informações geográficas na determinação da aptidão agrícola das terras. Revista Brasileira de Ciência do Solo, Viçosa, v.19, n.1, p.133-139, 1995.

MOURA, L. do C.; MARQUES, A.F.S. e M.; HADAD, R.M.; ANDRADE, H.;ALVES, H.M.R. - A aptidão agrícola das terras do município de Machado/ MG e a cafeicultura. Caderno de Geografia, Belo Horizonte, v.17, n.28, p.141-162, 2007.
NASCIMENTO, P. C.; GIASSON, E.; INDA, Jr. A. V. Aptidão de uso dos solos e meio ambiente. In: Fórum Solos e Meio Ambiente. 2004, Santa Maria. Anais..., Santa Maria: 2004. p. 41-57.

PEREIRA, L. C.; SILVEIRA, M. A.; LOMBARDI NETO, F. Agroecologia e aptidão agrícola das terras: as bases científicas para uma agricultura sustentável. Revista Brasileira de Agroecologia, Jaguariúna, v. 1, n. 1, p. 823-826, 2006.

PEREIRA, L. C. Aptidão agrícola das terras e sensibilidade ambiental: proposta metodológica. 2002. 122 f. Tese (Doutorado em Engenharia Agrícola) - Universidade Estadual de Campinas, Campinas, 2002. Disponível em: http://libdigi. unicamp.br/document Acesso em: 14 ago. 2011.

RAMALHO FILHO, A.; PEREIRA, E. G.; BEEK, K. J. Sistema de Avaliação da Aptidão Agrícola das Terras. 2.ed. Rio de Janeiro: EMBRAPACNPS, 1983.

RAMALHO FILHO, A.; BEEK, K. J. Sistema de Avaliação da Aptidão Agrícola das Terras. 3.ed. Rio de Janeiro: EMBRAPA-CNPS, 1995. 65p.

SAlBEGO, A. G.; GIOTTO, E.; MADRUGA, P. R. Geoprocessamento Aplicado ao Diagnóstico e Espacialização da Infra-estrutura Viária Rural. Guarapuava-PR: Revista do Centro de Ciências Agrárias e Ambientais, Chapadinha, v. 2, n. 2, 2006. Disponível: http://www.unicentro.br/editora/ revistas/ambiencia/v2n2/6-\%20179-195.pdf Acesso em: 20 ago. 2011.

SILVA, E. B.; NOGUEIA, R. E.; UBERTI, A. A. A. Avaliação da aptidão agrícola das terras como subsídio ao assentamento de famílias rurais, utilizando Sistemas de Informações Geográficas. Revista Brasileira de Ciência do Solo, Viçosa, v. 34, n. 6, p. 1977-1990, 2010.

VASCONCELOS GOMES, J. B.; LUMBRERAS, J.F.; OLIVEIRA, R.P.; BHERING, S. B.;ZARONI, M. J.; ANDRADE, A.G. \& CALDERANO, S.B. Aptidão para reflorestamento das Sub-bacias dos Canais do Mangue e do Cunha, município do Rio de Janeiro. Revista Brasileira de Ciência do Solo, Viçosa, v. 29, n. 3, p. 459-466, 2005. 